E.L.U.A., 1, 1983, págs. 325-342

\title{
RECENSIONES
}

Dolores Azorín Fernández

(Universidad de Alicante)

\section{LA LEXICOGRAFÍA}

De la lingüistica teórica a la lexicografía práctica

Por G. Haensch, L. Wolf, S. Ettinger y R. Werner, Madrid, Gredos, 1982 (Manuales, 56).

\section{PRESENTACIÓN}

Ciertamente, la lexicografía puede preciarse, entre las restantes disciplinas lingüisticas, de poseer una dilatada tradición "que se remonta no sólo a Grecia y Roma en los orígenes de la civilización occidental, sino también a las culturạs más viejas del oriente próximo y lejano» (1). Sin embargo, a pesar de su probada veterania, la actividad lexicográfica ha permanecido tradicionalmente al margen de los avances que, en otros ámbitos de la investigación, ha llevado a cabo la lingüística moderna. Esta situación de precariedad es achacable fundamentalmente al marcado carácter utilitario del producto lexicográfico (diccionarios, vocabularios, glosarios, etc.), que, llamado a cumplir una función eminentemente práctica, situó a la lexicografía en la órbita de las tareas artesanales, alejándola de la especulación lingüística y del desarrollo de la ciencia del lenguaje. Cabe recordar a este propósito el hecho de que Julio Casares -innovador, por otra parte, tanto en la teoria como en la práctica lexicográficas-, al diferenciar como disciplinas lexicología de lexicografía, no vacilaba en conceder a la primera el rango de

(1) J. FERNANDEZ SEVILLA, Problemas de lexicografia actual, Bogotá, Publicaciones del Instituto Caro y Cuervo, 1974, pág. 13. 
ciencia, mientras que la segunda era definida como técnica o arte:

[...] de igual manera que distinguimos una ciencia de la gramática y un arte de la gramática, podemos distinguir dos facultades, que tienen por objeto común el origen, la forma y el significado de las palabras: la lexicologia, que estudia estas materias desde un punto de vista general y científico, y la lexicografía, cuyo cometido, principalmente utilitario, se define acertadamente en nuestro léxico como el 'arte de componer diccionarios'. (2)

Sin embargo, la finalidad práctica del quehacer lexicográfico no es, en absoluto, un impedimento para que la lexicografía se funde en el conocimiento científico del lenguaje y desarrolle, por tanto, una teoría y metodología propias, que han de surgir, necesariamente, de la síntesis entre lexicografía práctica y lingüística teórica. Este es el propósito que anima a los autores del manual objeto de nuestro comentario, quienes, a lo largo de las 563 páginas de que consta el libro, ofrecen una acertada introducción a los problemas tanto teóricos como prácticos de la lexicografía actual.

\section{PROPÓSITO Y PLAN DE LA OBRA}

En el capítulo introductorio, se subraya la necesidad de una obra de conjunto que establezca ese deseado puente entre la lexicografía práctica y los más recientes desarrollos de la lingüística moderna:

Nuestra introducción busca un término medio entre la investigación lingüistica y su aplicabilidad lexicográfica. Como ya hemos destacado, constituye un intento de tener en cuenta, en una medida adecuada, una serie de resultados de la ciencia lingüistica y de abordar problemas esenciales de la lexicografía con su problemática lingüística. Nuestro enfoque está determinado, además, por el empirismo de la práctica lexicográfica... (3)

(2) J. CASARES, Introducción a la lexicografia moderna, Madrid, Consejo Superior de Investigaciones Cientificas, 1969, Anejos de la R.F.E., LII, pág. 11.

(3) HAENSCH, WOLF, ETTINGER y WERNER, La lexicografia. De la lingüistica teórica a la lexicografia práctica, Madrid, Gredos, 1982 (Manuales, 46), pág. 18. En lo sucesivo, nos limitamos a consignar el número de página tras cada cita textual de la presente obra, prescindiendo de las anotaciones a pie de página. 
Partiendo de este presupuesto inicial, la obra se estructura en nueve capitulos, donde se abordan los siguientes temas:

1. Introducción (por G. Haensch y L. Wolf), págs. 11-20.

2: Léxico y teoria general del lenguaje (por R. Werner), págs. 21-94.

3: Tipologia de las obras lexicográficas (por G. Haensch), págs. 95187.

4: La unidad léxica y el lema (por R. Werner), págs. 188-232.

5: Formación de palabras y fraseología en lexicografía (por S. Ettinger), págs. 233-258.

6: La definición lexicográfica (por R. Werner), págs. 259-328.

7: Signo lingüístico y estructuras semánticas (por L. Wolf), págs. 329-358.

8: La variación lingüistica en lexicografía (por E. Ettinger), págs. 359-394.

(9) Aspectos prácticos de la elaboración de diccionarios (por G. Haensch), pág. 395-536.

Cierran el libro dos indices; uno de materias (págs. 537-547) y otro de nombres propios (pp. 549-556) que facilitan en extremo la consulta de la obra. Hay que añadir, además, que cada capítulo se acompaña de una nutrida selección bibliográfica acerca de los temas específicos tratados, lo que convierte al presente manual en una eficaz guia de acercamiento a los diversos problemas con que se enfrenta tanto la teoría como la práctica lexicográfica.

\section{DESCRIPCIÓN DEL CONTENIDO DE LA OBRA}

Es imposible, en el estrecho marco de una recensión, dar pormenorizada cuenta de los múltiples aspectos abordados en el presente manual, no sólo por la magnitud cuantitativa de la obra, sino también en atención a la complejidad y diversidad de soluciones que plantean los diversos temas examinados. Aplicamos, pues, en nuestro comentario, un criterio selectivo, procurando en todo momento destacar aquellos aspectos que, por su novedad, puedan considerarse como aportaciones originales -al menos, respecto de la bibliografía existente en el ámbito hispánico- en el tratamiento de los principales problemas que afectan a la teoría lexicográfica y a su praxis especifica.

Capítulo 2: Léxico y teoria general del lenguaje.

R. Werner replantea aquí el problema de la especificidad de la lexicografía como disciplina lingüística; para ello, parte del funcionamiento 
del lenguaje en general y de sus posibilidades de descripción, deslindando el papel que corresponde al componente léxico en el proceso de la comunicación lingüística, así como los distintos enfoques que pueden aplicarse a su estudio.

Tras la caracterización del signo lingüístico (4), presenta Werner un esbozo de los factores que intervienen en la comunicación:

- Contenido del mensaje.

- Situación de comunicación.

-Conjunto de significantes.

El emisor parte del contenido del mensaje y de la situación; estos dos conjuntos determinarán la selección y combinación de los significantes que el emisor tiene que realizar.

El contenido es; de por sí, difícil de definir. Un enunciado lingüístico puede interpretarse como una exhortación, una orden, etc.; mas, por encima de esto, el contenido de un enunciado, hay que definirlo básicamente como una predicación; entendiendo por tal: la relación del enunciado lingüístico (como conjunto de significantes) con la idea que expresa:

[...] la frase El niño está subiendo la escalera se compone de elementos identificantes y predicantes. Con El niño se identifica una idea de la realidad, sobre la que se afirma algo [...] Con está subiendo la escalera se predica algo de la idea de la realidad 'El niño'. (Pág. 49)

Por tanto, se puede considerar la predicación como el contenido del enunciado lingüístico, y el hecho de que, por ejemplo, alguien sea exhortado, se podría explicar como función, no de los significantes del enunciado, sino de la predicación transmitida al receptor. A tenor de lo expuesto, Werner propone el siguiente deslinde terminológico:

-Contenido: término genérico para referirse a la función de signos lingüísticos (solos o en combinación con otros).

- Contenido ilocucionario: para la función de acción dèl signo.

(4) Hecho que lleva a cabo, en principio, a partir del modelo triangular de Ogden y Richards, dando cuenta de las relaciones entre forma de signo, contenido de signo y realidad. Sin embargo, este modelo, al insistir fundamentaimente en el código, prescinde de los diferentes papeles del emisor y del receptor del signo. Werner subraya, en este sentido, la superioridad del modelo trapezoidal de $K$. Heger que, al describir genéticamente el proceso de la denominación, reconstruye el camino que sigue el emisor para llegar desde el concepto a la forma de signo, a través del semema; o el que sigue el receptor, desde la forma de signo al concepto, invirtiendo el proceso. (Cf. K. Heger, "La semántica y la dicotomía de lengua y habla» en Teoría semántica, II, Madrid, Alcalá, págs. 135-209.) 
- Contenido proposicional: para la representación de una proposición.

- Contenido referencial: a la denominación de ideas por medio de significantes individuales (función denominadora).

Para explicar la relación exacta entre significante y contenido, hay que acudir a la segunda variable de la relación de dependencia de los componentes de un acto de comunicación: la situación comunicativa. Resulta útil distinguir por abstracción ciertas clases de factores de la situación de comunicación, tales como:

a) el conocimiento previo real que se supone en el interlocutor, que influye tanto en la selección de significantes por parte del emisor, como en la interpretación de los mismos por el receptor.

b) el tipo de relación social existente entre el emisor y el receptor, hecho que influye en la elección e interpretación de los significantes.

c) las convenciones sociales, normas morales, etc. de la comunidad.

d) el medio de comunicación utilizado.

La forma física de un enunciado lingüístico, o conjunto de significantes, es el tercer componente de un acto de comunicación, que, a su vez, puede ser desglosado en una serie de conjuntos parciales:

-Texto: conjunto total de significantes de un enunciado lingüístico.

-Proposición: conjunto de significantes con contenido proposicional (un texto puede constar de varias proposiciones).

- Monema: unidad significativa mínima a la que corresponde un semema.

-Sinmonema: significante compuesto por varios monemas.

-Distinguema: letras o sonidos distintivos de monemas

fonemas grafemas

Para establecer el alcance y objeto de aplicación de la lexicografía es necesario, además, tener en cuenta los modos de ser de la lengua, así como sus posibilidades de descripción científica. De este modo, comprobamos que una de las características de los signos lingüísticos es su doble existencia: a) como signos realizados; b) como signos virtuales pertenecientes a un código. Código que se caracteriza, a diferencia de otros, no sólo por su extremada complejidad sino, fundamentalmente, porque la correspondencia entre significantes y significados no siempre es recíproca e invariable. Esto es debido a las diferencias que se dan en los distintos códigos individuales. Por tanto, en una lengua hay que distinguir entre:

a) Sistema individual: la intuición de una persona determinada, en un momento determinado, acerca del sistema de correspondencia recí- 
proca entre significantes y contenidos, y de las reglas que posibilitan la comprensión con otros hablantes.

b) Discurso individual: la realización del sistema individual en un enunciado determinado.

c) Discurso colectivo: los elementos lingüísticos realizados por una comunidad humana.

d) Sistema colectivo: no hay que entenderlo como un código que existe repetidas veces de manera idéntica, sino como suma de elementos de una cantidad de sistemas individuales.

A todo esto hay que añadir que un sistema lingüístico individual puede pertenecer a varios sistemas colectivos. Para denominar, de una manera general, la relación jerárquica entre dos sistemas colectivos, existen los términos "subsistema» y "diasistema».

Ningún enfoque podrá aspirar a describir exhaustivamente el sistema colectivo, ni siquiera un solo sistema individual. La lingüística se ocupará, por tanto, de algún aspecto parcial de un sistema colectivo o de varios sistemas.

Llegados a este punto, Werner define el léxico como «un conjunto de significantes verbales o de signos (en la concepción bilateral del signo), que están por encima del nivel de los distinguemas y que pueden servir de partes componentes de proposiciones y textos [o dicho de otro modo] conjunto de monemas y sinmonemas del discurso individual, del discurso colectivo, del sistema lingüístico individual o del sistema lingüístico colectivo". (Pág. 91).

El léxico, así delimitado, es susceptible de distintos enfoques lingüisticos. De manera general, se pueden deslindar dos disciplinas que se ocupan especificamente de su estudio:

a) La lexicologia: que se aplica a la descripción de las regularidades y estructuras de la totalidad del léxico de un sistema individual o colectivo; si se trata de regularidades formales, hablaremos de morfologia léxica; si se trata de regularidades en las relaciones del léxico con otros factores de la comunicación (especialmente con el contenido de los significantes), nos encontraremos con la semántica léxica.

b) La lexicografía: que tiene por objeto la descripción individual de los monemas y sinmonemas de los discursos individuales y colectivos y de los sistemas individuales y colectivos.

Capitulo 3: Tipologia de las obras lexicográficas.

Los estudios lexicográficos recubren una amplia gama de codificaciones que, a veces, escapan a los más conspicuos intentos de clasificación. G. Haensch, consciente de esta dificultad, opta en el presente 
capítulo por una tipologización tripartita del producto lexicográfico, atendiendo a los siguientes criterios: a) punto de vista de la lingüística teórica; b) perspectiva histórico-cultural; c) punto de vista práctico.

A) desde el punto de vista de la lingüística teórica, las obras lexicográficas pueden agruparse según ciertos principios que derivan de:

1) Los modos de ser la lengua, criterio que clasifica a las obras,lexicográficas en: Codificaciones del discurso individual. Codificaciones del discurso colectivo. Codificaciones del sistema individual. Codificaciones del sistema colectivo.

2) Según los distintos enfoques de descripción lingüística, se pueden distinguir muchos tipos de codificaciones lexicográficas, las fundamentales son:

2.1. - Las que tienen en cuenta el punto de vista de los participantes en el acto de comunicación:

2.1.1.- El emisor: Diccionarios onomasilógicos

-ideológicos

-por materias

-por conceptos

Diccs. que ofrecen pautas para

—ortoépicos

la codificacion lingüistica

-ortográficos

-de formación de palabras

-construcción

y régimen

-colocaciones

- de dudas

2.1.2.- El receptor:

-Diccionario semasiológico stricto sensu.

-Diccionario de modismos y fraseologia.

-Diccionario de neologismos, extranjerismos.

—Diccionario plurilingües —Bilingües

—multilingües

2.2.- No tienen en cuenta específicamente la función del interlocutor en la comunicación:

2.2.1. - Diccionario inverso o de rimas (finalidad científica).

2.2.2. Diccionario de frecuencias o estadístico.

2.2.3. - Diccs. basados en las relaciones estructurales del léxico

Dicc. de sinónimos

Dicc. de antónimos

Dicc. de estilo 

2.2.4. - Tienen en cuenta el desarrollo histórico del léxico

Diccionario histórico
Diccionario etimológico

3) Un tratamiento especial requieren las llamadas enciclopedias, que presentan dos modalidades:

3.1. - La enciclopedia o tipo puro, recoge conocimientos humanos sobre determinadas materias, agrupados en artículos mediante significantes lingüísticos que figuran como lemas.

3.2.- El diccionario enciclopédico, que combina la descripción enciclopédica y la descripción lingüistica.

B) Desde una perspectiva histórico-cultural, Haensch traza en este apartado una breve síntesis descriptiva de la práctica lexicográfica, atendiendo a las motivaciones específicas que, en cada momento, determinaron la configuración de cada tipo de obra, prestando particular atención al desarrollo de la lexicografía hispánica.

Si las primeras manifestaciones del quehacer lexicográfico respondían a la necesidad de explicar ciertos términos, que debido a la evolución de la lengua eran ya de difícil interpretación -origen de las conocidas glosas medievales-, con el humanismo se inician las grandes compilaciones lexicográficas, especialmente en el terreno bilingüe. Buena muestra de ello son el Universal vocabulario (1490) de Alonso de Palencia, primer diccionario latín-castellano que se publica en España, $y$, dos años más tarde, el Vocabulario de latín en romance de Nebrija, al que seguirá inmediatamente el Vocabulario de romance en latín, obra en la que manifiesta, por primera vez, una tendencia normativa en la lexicografía española.

El diccionario normativo unilingüe surgirá intimamente ligado a las academias de la lengua, cuya labor prescriptiva se extiende también a la gramática, ortografía, etc.; precursor, en este sentido, es el Vocabulario degli Academici della Crusca (1612); aunque la época por excelencia del diccionario normativo es la llustración; el Dictionnaire de l'Academie Française (1694), de gran repercusión en toda Europa, el Diccionario de Autoridades de la Real Academia Española (1726-1739), el Dictionary of the English Language (1755), de Samuel Jonhson, son los principales exponentes de esta modalidad.

La lexicografía descriptiva es, por el contrario, de más reciente aparición y, en España, existe en este terreno una gran dependencia del Diccionario académico en cuanto a métodos y criterios de selección.

En la actualidad, la práctica lexicográfica se ha visto enriquecida con la aparición de nuevos tipos de diccionarios, como los ideológicos, de uso, etc., así como con la introducción de criterios más científicos 
que derivan, en última instancia, de las aportaciones de la lingüistica moderna -especialmente de la escuela funcional-estructuralista- al conocimiento real de las lenguas.

C) Desde un punto de vista estrictamente pragmático, cabe agrupar a las obras lexicográficas atendiendo a las caracteristicas reales que en ellas se presentan. A juicio de G. Haensch, estas características son:

1.- Formato y extensión: aspecto externo, si bien condiciona el número de entradas. Generalmente, la finalidad del diccionario es lo que limita su extensión.

2.- Carácter lingǘístico o enciclopédico: existen diccionarios de materias o enciclopedias y diccionarios de la lengua o lingüísticos.

3.- Sistema lingüístico en que se basa: el diccionario puede basarse en el sistema lingüistico individual de su(s) autor(es), como es el caso del Dictionnaire de l'Academie Française; o bien en un corpus, previamente seleccionado, de diferentes textos, como nuestro Diccionario de Autoridades.

4.- Número de lenguas: que divide a los diccionarios en unilingües y plurilingües.

5.- Selección del Jéxico.

5:1. Vocabulario general: no son generales ni exhaustivos. Se llaman "generales" porque recogen una representación aceptable del vocabulario usual de una lengua. Ej. el Diccionario de la Real Academia Española, el Diccionario del Uso del Español de Maria Moliner, etc.

5.2. Vocabulario parcial: se distinguen distintos tipos de vocabularios parciales, siempre con referencia a la lengua concebida como diasistema:

5.2.1. Vocabulario parcial con marcación diatópica: Ej., Alcalá Venceslada, Vocabulario andaluz, Madrid, 1951.

5.2.2. Vocabulario parcial con marcación diastrática: L. Besses, Diccionario del argot español, Barcelona, s.a.

5.2.3. Vocabulario parcial con marcación diatécnica: Cossio, «Vocabulario taurino autorizado", en Los Toros, 1943.

5.2.4. Vocabulario parcial con marcación diafásica: Cela, Diccionario secreto, Madrid, 1971.

5.2.5. Vocabulario parcial con marcación diaintegrativa: Alfaro, Diccionario de anglicismos, Madrid, 1964.

5.2.6. Vocabulario parcial con marcación dianormativa: Santamaría, Diccionario de incorrecciones del lenguaje, Madrid, 1975.

5.3. Codificación exhaustiva o selectiva: Tanto los diccionarios generales como los parciales o especializados podrian ser exhaustivos 0 selectivos. Los Thesauri son los que más se acercan al tipo de codificación exhaustiva. Entre los selectivos hay que distinguir entre el Diccio- 
nario de uso, que selecciona las palabras más corrientes haciendo hincapié en el uso contextual; y el Diccionario de aprendizaje, más restringido que el anterior. Los llamados diccionarios de frecuencias se cuentan también entre las codificaciones selectivas.

5.4. Criterio cronológico: que distingue entre diccionarios sincrónicos y diacrónicos, entre estos últimos, los más usuales son el diccionario histórico y el diccionario etimológico.

5.5. Carácter prescriptivo o descriptivo: específicamente prescriptivos son los diccionarios académicos, escolares, de dudas, ortográficos, etc., Ios diccionarios descriptivos tienen por misión recoger una selección representativa del vocabulario usado realmente.

6.- Ordenación de materiales: es otro criterio de clasificación, puesto que la ordenación condiciona la llamada «macroestructura» del diccionario. Hay dos tipos fundamentales: el diccionario semasiológico y el diccionario onomasiológico.

7.- Finalidades especificas: hay diccionarios muy específicos como los de abreviaturas, onomásticos, de refranes y frases, etc., no recogidos en los anteriores criterios de clasificación.

Capítulo 4.- La unidad léxica y el lema.

Uno de los principales problemas que tiene planteados la lexicografía teórica es el que se refiere a las unidades que deben figurar en la nomenclatura de los diccionarios. $R$. Werner se encarga en este capitulo del planteamiento general de la cuestión, haciendo especial hincapié en el enfrentamiento existente en este terreno entre la lingüística teórica y la práctica lexicográfica. El propio Werner, en el capítulo 2 de este manual, definía el léxico de una lengua como: el conjunto de monemas y sinmonemas del discurso individual y colectivo, y del sistema individual y colectivo; entendiendo por monema - tal como propone Martinet- 'la unidad mínima significativa a la que corresponde un semema'. La lingü istica estructural distingue, asimismo, entre dos clases de monemas: los que tienen contenido léxico y los que son portadores de contenido gramatical; escisión que, a su vez, suscita nuevos interrogantes a la teoría lexicográfica; puesto que, ya no se trata simplemente de dilucidar si el monema debe o no considerarse como la unidad de tratamiento lexicográfico, sino también qué tipo de monemas son susceptibles de dicho tratamiento. Nos encontramos, pues, ante la dicotomía 'léxico v.s. gramática' que, referida al diccionario, sigue suscitando opiniones encontradas entre los lingüistas que se han ocupado del tema (5).

(5) Coseriu, por ejemplo, plantea de manera tajante la distinción entre léxico y gramática, a 
Los monemas gramaticales - dejando a un lado la cuestión de si es lícita o no su inclusión en el diccionario- presentan la dificultad de que su contenido no puede delimitarse con los medios usuales de la definición lexicográfica que, en los repertorios monolingües, presenta dos modalidades básicas: definición por género próximo y diferencia específica y definición por sinónimos. Los monemas gramaticales deberian definirse, en todo caso, mediante la exposición detallada de sus condiciones de uso. Por otro lado, los diccionarios que recogen monemas gramaticales no observan un criterio exhaustivo; ya que, por ejemplo, incluirán como lemas a las proposiciones, pero nunca harán lo mismo con los morfemas de tiempo, caso, etc. Esto se debe fundamentalmente a que la lexicografía se basa en la palabra como unidad de tratamiento y no en el monema. Efectivamente, el concepto de lema no se apoya en una definición lingüística, sino en la tradición lexicográfica. El lema, llamado también palabra clave o voz guía, es la unidad que encabeza los artículos de un diccionario y su conjunto constituye la macroestructura del mismo. Werner se pregunta sobre el fundamento de esta tradición multisecular, al paso que argumenta sobre las ventajas que ofrece una lexicografía apoyada en la palabra como unidad de tratamiento. Las razones son múltiples; por un lado, el diccionario no se elabora exclusivamente para lingüistas, sino que se dirige a un usuario heterogéneo; por otro, hay que tener en cuenta que la unidad "palabra» tiene una importancia cultural enorme, su arraigo en la conciencia humana va íntimamente ligado al proceso de aprendizaje de las lenguas. Por último, la delimitación gráfica de la palabra en el texto constituye un eficaz instrumento de identificación; quizás sea esta última, la principal razón del mantenimiento de la palabra como unidad

la hora de deslindar el objeto de aplicación de la lexicología; entendiendo por léxico únicamente raquellas palabras de una lengua que corresponden a la organización inmediata de la realidad extralingülstica [...] A este respecto hay que distinguir tres clases de palabras: 1) $\mathrm{Pa}$ labras lexemáticas, que estructuran y representan la realidad [...] como p.e. 'hombre', 'correr', 'blanco', etc. 2) Palabras categoremáticas, que presentan tan sólo la forma de estructuración de lo extralingülstico: 'yo', 'éste', 'ahora', etc. 3) Palabras morfemáticas, que no funcionan de modo inmediato como configuradoras del amundon, sino sólo, en relación con otras palabras [.... ' $y$ ', ' $O$ ', 'sobre', etc. Sólo las palabras lexemáticas pertenecen con derecho propio al léxico $y$, en consecuencia, al objeto propio de la lexicología ( $E$. Coseriu, "Semántica y gramática” en Semántica, gramática y universales, Madrid, Gredos, 1978, (Estudios y Ensayos, 280), pág. 133).

Por el contrario, otros autores abogan por la inclusión en la nomenclatura de los diccionarios de estas unidades no estrictamente lexemáticas, lo que redundaría en la utilidad de los mismos, considerados como instrumentos al servicio de un mejor uso de la lengua. Sobre este particular y, en general, para todo lo concerniente a las relaciones e interferencias entre léxico y gramática en los distintos tipos de codificaciones lexicográficas, vid. el artículo de $M$. Alvar Ezquerra, «Gramática y diccionario», Lingülstica Española Actual, IV, 1982, págs. 151-207, donde se hallará, además, una completa bibliografía sobre el tema. 
de tratamiento lexicográfico, pese a su manifiesto pragmatismo. A pesar de su evidente utilidad, una lexicografía basada en la palabra conlleva otros problemas como son el tratamiento de los monemas formadores de palabras y el de los sinmonemas. Werner se muestra partidario de la inclusión de los primeros en la nomenclatura del diccionario como lemas independientes, o bien, confeccionar listas complementarias de afijos. En cuanto a los sinmonemas, siempre de que se trate de unidades lexicalizadas, entrarán también en el diccionario, especificándose el criterio general seguido por el lexicógrafo a la hora de su lematización.

Capítulo 5.-Formación de palabras y fraseología en la lexicografía.

Si bien la formación de palabras y de unidades fraseológicas no puede exponerse de manera directa en el diccionario, sus mecanismos productivos han de tenerse en cuenta en la práctica lexicográfica. A este propósito, Stefan Ettinger examina los resultados más sobresalientes de la investigación teórica sobre el tema (6), para, posteriormente, referirlos a la elaboración de diccionarios.

El lexicógrafo habrá de tener en cuenta las modernas teorías sobre la formación de palabras y, especialmente, habrá de considerar la frecuencia de determinados procedimientos formadores para decidir si éstos deben figurar o no en el diccionario.

En cuanto a las unidades fraseológicas, se señala la conveniencia de su inclusión en el diccionario. Normalmente, éstos suelen acoger en su microestructura determinadas combinaciones de la palabra clave con otros lexemas, sobre todo, cuando el significado de las mismas no es deducible directamente de sus componentes. Este criterio debería de ampliarse a otras formaciones habitualizadas; tal es el caso de las colocaciones, o tendencias sintáctico-semánticas de las palabras a adoptar un número limitado de combinaciones.

Capítulo 6.- La definición lexicográfica.

Del mismo modo que la palabra se mantiene como unidad básica de

(6) Así, resume las aportaciones surgidas: a) en el seno de la lingüistica tradicional que, por su orientación preferentemente histórica, no son aprovechables de manera general para la lexicografia. b) las contribuciones de la lingülstica estructural, con especial atención a las teorias de $E$. Coseriu, que engloba la formación de palabras en el marco de las estructuras lexemáticas, ofreciendo resultados válidos para la lexicografla, sobre todo, en el terreno de la derivación. c) La gramática generativa, a su vez, aporta soluciones aplicables al estudio y descripción lexicográfica de los compuestos. 
tratamiento en las distintas codificaciones lexicográficas, a pesar del reconocimiento de otras unidades lingüisticas; en el caso de la definición lexicográfica, una tradición similar, apoyada fundamentalmente en criterios pragmáticos, impide que el diccionario incorpore en su parte definitoria las técnicas de descripción del significado que proporciona la semántica moderna: nos referimos especialmente a los análisis sémicos. R. Werner justifica este estado de cosas atendiendo al carácter provisional de este tipo de análisis, terreno en el que todavía quedan algunas cuestiones sin resolver (7).

Basándose en los resultados de la práctica lexicográfica, el autor intenta una tipología de las técnicas de definición distinguiendo dos ámbitos diferenciados: el del diccionario semasiológico unilingüe y el de los diccionarios plurilingües. En el primer caso, se observan dos procedimientos básicos:

a) La técnica de la paráfrasis lingüistica, que consiste en parafrasear el semema que corresponde a la unidad de descripción, mediante un sintagma cuyo contenido referencial sea igual al del semema que hay que definir. El procedimiento es válido cuando la combinación de sememas del definidor contiene los mismos semas que el semema del definido.

b) La instrucción semántica mediante la indicación de sinónimos: esta definición suele ser insuficiente, puesto que los contenidos de unidades léxicas diferentes no se corresponden nunca por completo. Dos piezas léxicas pueden ser equivalentes en cuanto a su contenido referencial, pero pueden no ser intercambiables en todos los contextos o situaciones, si su contenido ilocucionario difiere.

La utilización de estas dos técnicas hace a menudo inevitable que el lexicógrafo caiga en las conocidas definiciones circulares.

La definición en los diccionarios plurilingües cuenta, a su vez, con una problemática especifica, susceptible de un tratamiento diferenciado. La principal dificultad es, sin duda, la falta de correspondencia entre las estructuras léxicas de las lenguas que se codifican en un diccionario de estas características. Partiendo de este presupuesto inicial, el lexicógrafo no debe aspirar a producir en la lengua de destino un texto cuyo contenido corresponda exactamente al de la lengua de

(7) Por ejemplo, si determinados semas podrian descomponerse aún más; si sólo hay que considerar como rasgos distintivos los que atañen al contenido referencial; el problema de los límites entre componentes lingüisticos y conocimiento del denotatum; por último, la inexistencia de acuerdo entre las distintas escuelas lingülsticas en cuanto a las normas para la notación formal del análisis sémico. 
origen; sino ofrecer en la lengua de destino otro que concuerde en el mayor número de elementos esenciales con el de la lengua de origen.

Finalmente, Werner aborda el espinoso tema del tratamiento lexicográfico de la homonimia y polisemia. Analiza las distintas aportaciones de la lingüistica teórica en este campo, señalando su escasa aplicabilidad a la práctica lexicográfica (Cf. págs. 297-312). Su propuesta concreta, de marcado carácter pragmático, pasa por renunciar a la teoria de la llamada relación de consubstancialidad cuantitativa del signo lingüístico; si se sustituye esta relación por la de la simple atribución recíproca que se da entre el significante y su contenido lingüístico, no habría por qué reunir en un solo significante varios sememas; ello traería como consecuencia la desaparición de la distinción entre polisemia, polimorfismo y homonimia - desde este punto de vista sólo habría homonimia-, lo que comportaría muchas ventajas para el diccionario semasiológico que podría presentar, en este caso, un sólo lema por significante; si bien, las formas la flexión habría que considerarlas también como lemas; es decir, prever un lema por cada paradigma de flexión.

Capitulo 7.- Signo lingüistico y estructuras semánticas.

L. Wolf recoge en este capítulo las posibilidades de una lexicografía basada en las estructuras semánticas. El hecho de que las compilaciones lexicográficas hayan sido - y continúen siendo- mayoritariamente alfabéticas, no significa que en la historia de nuestra disciplina no se hayan producido intentos de clasificación del vocabulario según grupos de conceptos o materias (8). A partir del siglo XIX, por influencia de las clasificaciones científicas en el dominio de las ciencias de la naturaleza, empieza a plantearse de un modo serio y continuado la realización de este tipo de obras; interés que vino a acrecentarse tras la publicación del Begriffssystem de Hallig y von Wartburg; quienes llamaron la atención sobre la utilidad de un sistema de referencia extralingüístico como base objetiva de la lexicografía. Sin embargo, la idea de un sistema conceptual extralingüístico, esto es, independiente de una lengua dada, plantea a juicio de Wolf dos problemas fundamentales. De un lado, si se acepta la hipótesis de que el pensamiento está ligado a la

(8) Un temprano ejemplo, en este sentido, lo constituye la obra de Alfonso de Palencia -cronológicamente, el primero de nuestros lexicografos - titulada Opus Sinonymorum, aparecida en Sevilla en 1491. (Para una descripción completa de la labor lexicografica de Palencia, vid. R. Alemany, «Un antecedente olvidado de Antonio de Nebrija: la obra lexicográfica de Alfonso de Palencia», Item, 5, 1981, págs. 119-132.) 
lengua, y a una lengua determinada, habremos de concluir que no existen conceptos dados de antemano; si, por el contrario, mantenemos que lo simbolizado por la lengua existe a priori, entonces caemos en el error de considerar a las lenguas como meras nomenclaturas. Desde Humboldt se ha venido defendiendo la teoría de la vinculación de los conceptos a la estructura de las lenguas; es decir, las lenguas dividen y configuran la realidad según patrones internos que varian de lengua a lengua. Según esto, un sistema de referencia extralingüístico no puede ser base para la lexicografía hasta tanto no se compruebe la existencia de categorias conceptuales independientes de las lenguas, tarea ésta que no compete a la lingüística.

Para Wolf, un enfoque onomasiológico que pretenda no caer en descripciones tautológicas, habrá de basarse en aquellos análisis semasiológicos que, de alguna manera, rebasan los límites del signo mismo. Una posibilidad, en este sentido, ofrecen los ordenamientos de campos léxicos, a la manera de Pottier, Coseriu, Geckeler, etc.; puesto que en este tipo de estructuraciones surgen conceptos que no tienen correspondencia léxica en una lengua determinada.

\section{Capitulo 8. - La variación lingüistica en lexicografía.}

Al no existir para ninguna lengua natural una descripción completa de todos los procesos productivos de formación de palabras, lo que permitiría a los diccionarios dar instrucciones detalladas para la interpretación de nuevas unidades léxicas, éstos se convierten, en la mayoría de los casos, en registros retrasados e incompletos de la norma; y, puesto que en el estadio actual de la investigación, un diccionario basado en el sistema es inviable a todas luces, sólo queda el recurso de la norma como base de las codificaciones lexicográficas. Actualmente, el concepto de norma ha sufrido una extensión considerable, de modo que, a la norma en sentido tipológico de Coseriu, se oponen hoy dos tipos de normas:

a) La norma estadistica, que abarca todo lo que se acepta en una comunidad lingüística como uso normal y que puede registrarse estadisticamente. La norma estadistica o de uso cobra cada dia mayor importancia para la lexicografía aplicada, puesto que acerca al lexicógrafo a una representación objetiva del vocabulario.

b) La norma prescriptiva, puede definirse como un registro lingüístico que queda declarado como obligatorio para todos los hablantes de una comunidad. Desde el punto de vista lingüístico es sólo una entre las muchas normas que coexisten en una lengua. El mantenimiento de la norma prescriptiva como soporte de la lexicografía, se vuelve cada 
día menos defendible; sin embargo, el diccionario no puede prescindir de ella, pero sólo en la medida en que tampoco puede prescindir de otras normas existentes.

Por lo que se refiere a los niveles y registro lingüísticos y a su papel en el diccionario, Ettinger subraya el hecho de que, mientras la mayoría de las escuelas lingüísticas modernas, partieron en principio de la ficticia homogeneidad de la lengua, la lexicografía ha mostrado desde siempre una gran sensibilidad hacia las diferenciaciones dentro de la lengua, y se han tenido en cuenta en la práctica lexicográfica; si bien, no fueron tratadas con la suficiente claridad, ni se mantuvo tampoco un criterio exhaustivo; por ejemplo, se tenían en cuenta las diferencias geográficas y de estilo, pero, en menor medida, se apreciaron las variaciones diastráticas.

Dentro de la variación lingüística hay que tener presente también el caso de los tecnolectos o lenguas de especialidád que, desde el punto de vista lingüístico, habría que clasificar dentro de la diferenciación diastrática. Los tecnolectos plantean un serio problema a la lexicografía, debido a la gran proliferación de los mismos en las últimas décadas. El Grand Larousse contabiliza un total de 711 en el campo de las humanidades, 529 en el de las ciencias, a los que habría que sumar las terminologías no científicas. El lexicógrafo debe considerar con sumo cuidado los criterios de inclusión de las voces tecnolectales en el diccionario general, cosa que resulta extremadamente difícil, si tenemos en cuenta el constante trasvase de las mismas al vocabulario general.

Capítulo 9.- Aspectos prácticos de la elaboración de diccionarios.

En este extenso capítulo, el profesor Haensch presenta un digno colofón a los planteamientos teóricos que nutren el contenido de los apartados precedentes. Su propósito es ofrecer una guía para el inicio en las tareas concretas de la práctica lexicográfica, buscando siempre un término medio entre los postulados de la lingüística teórica y su aplicación a las técnicas de elaboración de diccionarios, basándose en las experiencias más recientes en el campo de la lexicografía aplicada.

De manera minuciosa y ordenada se exponen las distintas fases de que consta la elaboración de un proyecto lexicográfico, empezando por la selección de entradas, donde se hace especial hincapié en los criterios que se han de seguir para ello, finalizando con un detallado análisis de la organización que debe observarse en la parte definitoria de los artículos, teniendo en cuenta la orientación y finalidades específicas de cada producto lexicográfico en particular. De especial interés pedagógico es el apartado que se dedica a la fase de recogida y preparación 
preliminar de los materiales léxicos que han de servir de base, indicándose las fuentes a las que habrá de recurrir el lexicógrafo para la recopilación de sus datos, así como los instrumentos de trabajo necesarios para esta labor.

Finalmente, el autor dedica un epígrafe especial a los diccionarios plurilingües.

\section{A MODO DE CONCLUSIÓN}

El intento de acercar la praxis lexicográfica a los más recientes desarrollos de la lingüistica teórica, no puede menos que contribuir a la fundamentación científica del producto lexicográfico, mediante la adecuada renovación de su metodología específica. La obra de los profesores Haensch, Wolf, Ettinger y Werner constituye un notable esfuerzo en este sentido; esfuerzo tanto más provechoso puesto que, en ningún momento, los autores pierden de vista ese difícil equilibrio que debe guardar la obra lexicográfica entre su finalidad práctica y la exigencia del máximo rigor científico en la codificación del vocabulario.

Se podría acusar a los autores de La lexicografía de excesivo conservadurismo en las soluciones que aportan a determinados problemas - tales como el de la definición lexicográfica o el que atañe a la unidad de tratamiento-; sin embargo, dadas las características del producto lexicográfico, hemos de conceder al lexicógrafo el derecho de inclinar la balanza en favor de la utilidad, siempre que lo contrario suponga serias restricciones en cuanto a las posibilidades de uso del mismo.

En otros aspectos, por el contrario, el presente manual se muestra particularmente moderno. Así, la fundamentación del diccionario general en la denominada "norma estadistica» —obtenida gracias al concurso de las últimas técnicas de cuantificación de vocabulario-, la ampliación de la parte sintagmática de los artículos, inluyendo colocaciones y peculiaridades sintácticas del lema junto a los giros, modismos y fraseologia; la importancia concedida también a la parte paradigmática —sinónimos, antónimos, etc.-; la justa proporción y mejor caracterización de las variantes dianormativas, etc., orientan la elaboración del diccionario hacia el uso efectivo de la lengua, asegurando, así, su utilidad y adecuación a las exigencias de sus posibles usuarios. Todo ello supone una indudable renovación en el campo de la lexicografía aplicada, que debe mucho a esa tan deseable como necesaria interpenetración entre la lexicografía y la investigación teórica general del lenguaje. 


\section{BIBLIOGRAFÍA CONSULTADA}

ALVAR EZQUERRA, M. "Gramática y diccionario», Lingüistica Española Actual, IV, 1982, págs. 151-207.

ALEMANY FERRER, R., «Un antecedente olvidado de Olvidado de Antonio de Nebrija: la obra lexicográfica de Alonso de Palencia", Item, 5, 1981, págs. 119-132.

CASARES, J., Introducción a la lexicografía moderna, Madrid, Consejo Superior de Investigaciones Científicas, 1969, Anejos de la RFE, LII.

COSERIU, E., Semántica, gramática y universales, Madrid, Gredos, 1978 (Estudios y Ensayos, 280).

FERNÁNDEZ SEVILLA, J., Problemas de lexicografia actual, Bogotá, Publicaciones del Instituto Caro y Cuervo, 1974.

HEGER, K., Teoría semántica, II, Madrid, Alcalá, 1974. 